\title{
Role of Microstructural Features in Toughness Improvement of Zirconia Toughened Alumina
}

\author{
Olaniyi Fakolujo1* ${ }^{*}$, Ali Merati², Mariusz Bielawski², Manon Bolduc ${ }^{3}$, Michel Nganbe1 \\ ${ }^{1}$ University of Ottawa, Ottawa, Canada \\ ${ }^{2}$ National Research Council Canada, NRC Aerospace, Ottawa, Canada \\ ${ }^{3}$ Defence R\&D Canada (DRDC Valcartier), Quebec, Canada \\ Email: *ofako049@uottawa.ca
}

Received 7 December 2015; accepted 26 January 2016; published 29 January 2016

Copyright (C) 2016 by authors and Scientific Research Publishing Inc.

This work is licensed under the Creative Commons Attribution International License (CC BY).

http://creativecommons.org/licenses/by/4.0/

c) (i) Open Access

\begin{abstract}
Ceramics constitute an integral part of highly efficient armours due to their low density, high hardness, strength and stiffness. However, they lack toughness and multi-hit capability. Therefore, zirconia toughened alumina is investigated. The hardness is evaluated using Vickers, Knoop and instrumented indentations, while the fracture toughness is evaluated using the indentation technique and Charpy tests. The strength is evaluated using ring-on-ring, four point bend and drop weight tests. The Young's modulus is evaluated using the unloading instrumented indentation curves. Microstructure, porosity and density are characterised using ultrasonic scanning, Archimedes principle, optical and scanning electron microscopy. Results show an indentation size effect on all mechanical properties. A substantial improvement in toughness is achieved through retardation of crack initiation by tetragonal-to-monoclinic phase transformation in zirconia particles, crack deviation thanks to appropriate grain structure, as well as energy absorption by densification due to remaining porosity. This improved toughness is expected to promote multi-hit capability.
\end{abstract}

\section{Keywords}

Zirconia Toughened Alumina, Toughening Mechanisms, Fracture Toughness, Ballistic Performance, and Multi-Hit Capability

\footnotetext{
${ }^{*}$ Corresponding author.
}

How to cite this paper: Fakolujo, O., Merati, A., Bielawski, M., Bolduc, M. and Nganbe, M. (2016) Role of Microstructural Features in Toughness Improvement of Zirconia Toughened Alumina. Journal of Minerals and Materials Characterization and Engineering, 4, 87-102. http://dx.doi.org/10.4236/immce.2016.41009 


\section{Introduction}

Research on improving the ballistic performance of ceramics (including multi-hit capability) is a dynamic subject, as is made necessary by the ever-increasing threat level of bullets. So far, processing, characterisation and ballistic performance evaluations have highlighted the key roles of static mechanical properties and microstructure [1]. However, while the roles of hardness, sonic velocity, strength and density during ballistic events are relatively well understood, the relevance of fracture toughness is still unclear and controversial. Overall however, it is assumed that toughening of ceramics is synonymous for improved ballistic performance which has led to the widespread effort to reinforce ceramics with the aim of improving their strength and fracture toughness, and consequently the multi-hit capability [2]-[4]. Specifically, the multi-hit capability is shown to be a function of crack resistance that significantly affects the fragmentation process during ballistic impact on ceramics [5]. Of particular interest in toughening efforts is a synergistic combination of toughening mechanisms including microstructure design and particle or fiber reinforcement.

\section{Experimental}

Zirconia toughened alumina (ZTA) tiles with a size of $100 \times 100 \times 7 \mathrm{~mm}$ manufactured through a pressureless sintering process were obtained from NP Aerospace Inc. Specific details of the process and product are of a proprietary nature and are not disclosed here. Polished specimens were etched in air at $1300^{\circ} \mathrm{C}$ for 30 minutes. The microstructure was characterized using scanning electron microscopy (SEM: Hitachi and Carl Zeiss) with secondary electron and backscattered detectors (BSD) and energy-dispersive X-ray spectroscopy (EDS). Phases were characterised using X-ray diffraction (XRD) analysis. The average grain size and grain size distributions were determined using the line intercept method, as presented by ASTM E112-10. The porosity was measured through the Image $\mathrm{J}$ software.

The hardness of the material was characterised using three indentation methods including Vickers, Knoop, and nano indentation [6]. Vickers and Knoop hardness tests were performed according to ASTM C1327-09 and ASTM 1326-13, respectively, using loads ranging from 0.5 to $50 \mathrm{~kg}$ and 0.5 to $10 \mathrm{~kg}$, respectively. Nano indentation testing was run on ten cycles each for loads ranging from 0.1 to $2.5 \mathrm{~kg}$, and the hardness was evaluated according to Equation 1.

$$
H=\frac{F}{26.43 h^{2}}
$$

where $F$ is the applied load in kgf, and $h$ is the total penetration depth under nanoindentation.

The fracture toughness was evaluated using cracks measured at Vickers hardness indent corners using the non-standardised indentation fracture toughness (IFT) method [6]. The average of a minimum of 10 measurable indents at each load was considered and Equation (2) by Lawn et al. was used [7].

$$
K_{\text {IC }}=0.028\left(H a^{0.5}\right)(E / H)^{0.5}(c / a)^{-1.5}
$$

where $H$ is the hardness; $a$ is the half diagonal of the Vickers indent; $c$ is the crack length measured from the centre of the indent to the tip of the crack and $E$ is the modulus of elasticity calculated to be $330 \mathrm{GPa}$ using the rule of mixture and literature elastic modulus values of alumina and zirconia and their respective concentrations in the investigate material. The Young's Modulus was further corrected by considering porosity and the semi-empirical Equation (3) [8] as well as the Oliver-Pharr method using unloading nano indentation hardness test curves [6].

$$
E=E_{o} \exp ^{(-b p)}
$$

where $E_{o}$ is the elastic modulus of fully dense ZTA; $p$ is the porosity; and $b$ is a characteristic constant that is related to the particle stacking and pore shape and usually has values that range between 1 and 4.35.

In addition to the IFT method, Charpy impact and the drop tower tests were used to measure the toughness. Charpy testing was performed using unnotched specimens with size $50 \times 7 \times 7 \mathrm{~mm}$ on a TMI No $43-1$ impact tester with a total energy range of 2 to $15 \mathrm{~J}$ and an impact speed of $3.46 \mathrm{~m} / \mathrm{sec}$. The drop tower tests were performed according to ASTM D562-10, on $50 \times 50 \times 7 \mathrm{~mm}$ sample using a total assembly drop weight of $5.02 \mathrm{~kg}$ and an Intron Dynatup tester 9200. The strength was characterised using ring-on-ring (RoR), and 4-point bend tests according to ASTM standards C 1410 and C 1161c-15, respectively. A fracture mode study was conducted 
using fractured specimens from RoR tests and cracks in Vickers indention specimens at high load. Ultrasonic tests, the Archimedes test and porosity tests were used to calculate the density using Equation (4) [9].

$$
\rho=\rho_{o}(1-P)
$$

where $\rho_{o}$ is the pore-free density; $\rho$ is the density to be determined; $P$ is the porosity and $\rho_{o}$ taken as 4.08 .

\section{Results and Discussion}

\subsection{Microstructure}

The $\mathrm{ZrO}_{2}$ particles are of various sizes and shapes and are homogeneously dispersed in the alumina matrix (Figure 1(b)). They were found most often at grain boundaries adopting the shape of the triple point junctions. The XRD analysis (Figure 2) confirmed the second phase particles to be zirconia [10]. The alumina matrix grain structure is bimodal with finer equiaxed grains around $1 \mu \mathrm{m}$ in size and larger elongated grains with a grain size up to $10 \mu \mathrm{m}$ and a grain aspect ratio of about 2 .

While the use of zirconia as a second phase does prevent grain growth [11], it is also known to potentially impede densification during processing, leading to poor sintering ability [12], particularly during pressureless sintering [11]. This is reflected in the measured high porosity of $10.5 \%$ as shown in Figure 3(a), and corroborated by the image $\mathrm{J}$ analysis shown in Figure 3(b).

\subsection{Mechanical Properties}

\subsubsection{Hardness}

A summary of the mechanical properties is presented in Table 1. The variation of material hardness with applied loads is shown in Figure 4 plotted using the data presented in Table 2. This figure illustrates how the tested material shows a Vickers hardness of $1700 \mathrm{HV}$ at $1 \mathrm{kgf}$ that drops to $1500 \mathrm{HV}$ at higher test loads (2 kgf to $50 \mathrm{kgf}$ ). This is typical for the indentation size effect (ISE), which is primarily caused by incomplete and reversible deformations at low loads as shown in Figure 5(a) and Figure 5(b). Further potential causes of the in-

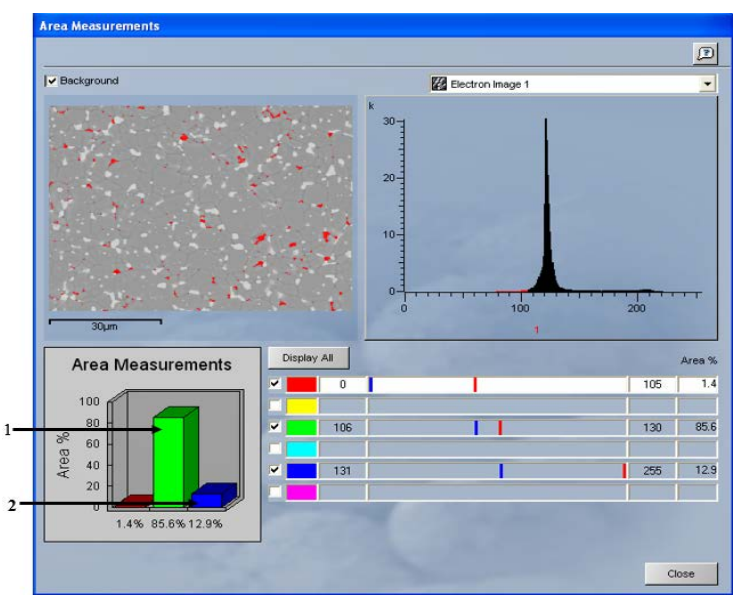

(a)

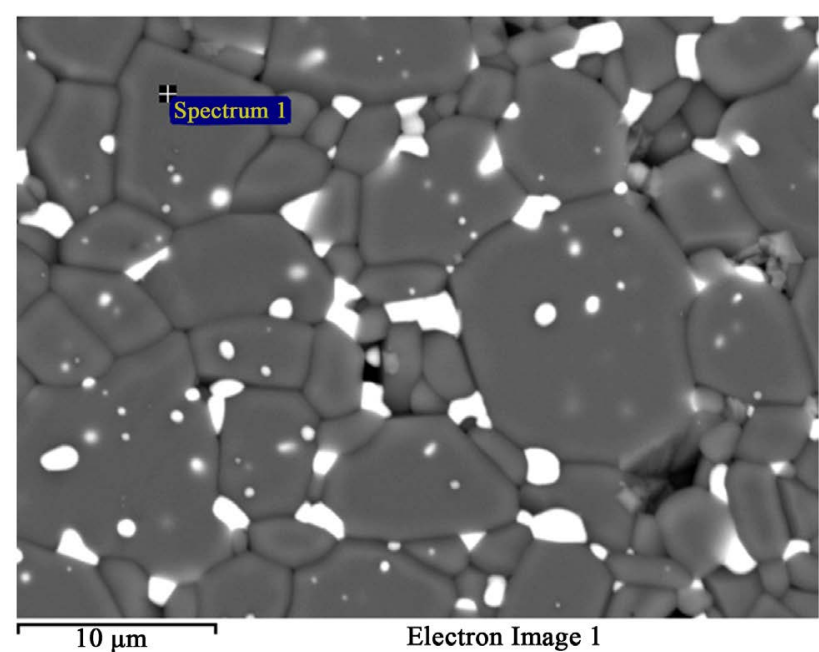

(b)

Figure 1. (a) EDS of the sample showing the two major phasesin ZTA. In the bar chart, (1) is alumina and (2) is zirconia; (b) SEM micrograph of the etched specimen used for the EDS analysis.

Table 1. Summary of mechanical properties.

\begin{tabular}{ccccc}
\hline Hardness (HV) & $\begin{array}{c}\text { Fracture toughness } \\
\left(\mathrm{MPam}^{1 / 2}\right)\end{array}$ & $\begin{array}{c}\text { Fracture strength } \\
(\mathrm{MPa})\end{array}$ & $\begin{array}{c}\text { Density } \\
\left(\mathrm{g} / \mathrm{cm}^{3}\right)\end{array}$ & $\begin{array}{c}\text { Young's } \\
\text { modulus }(\mathrm{GPa})\end{array}$ \\
\hline 1509 & 4.90 & 292 & 3.78 & 272 \\
\hline
\end{tabular}




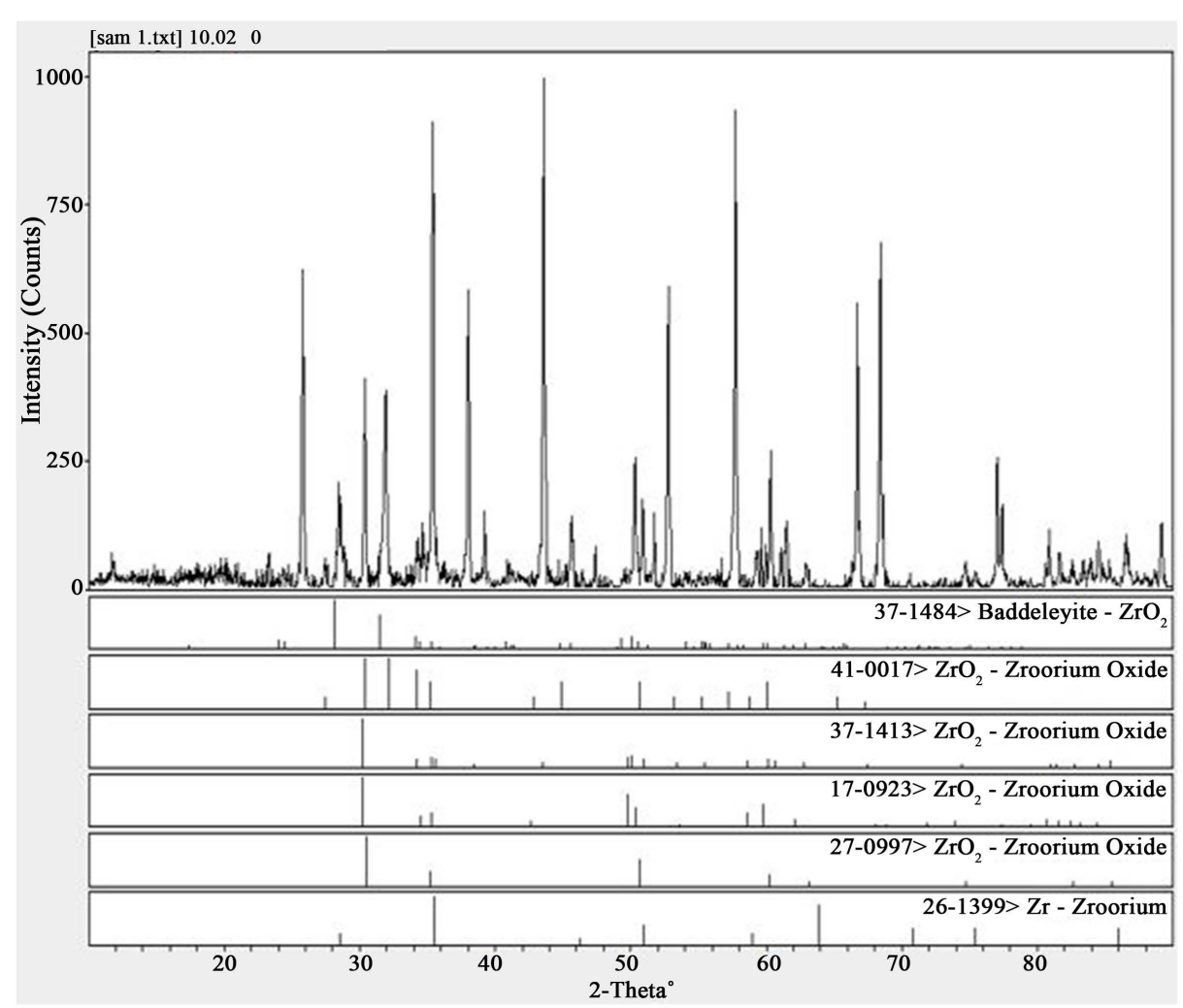

(a)

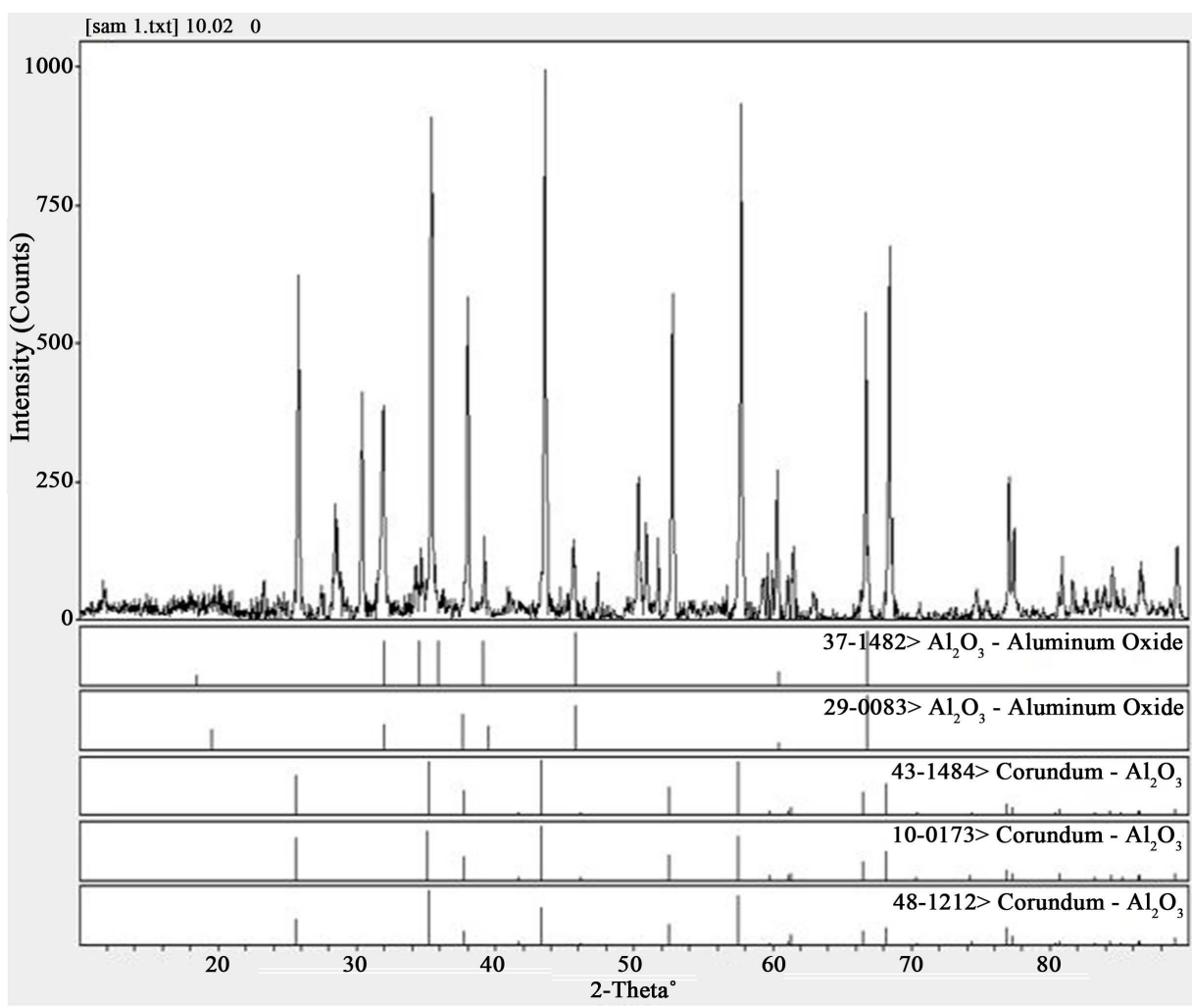

(b)

Figure 2. X-ray diffraction spectra for ZTA showing the two major phases: $\mathrm{ZrO}_{2}$ and $\mathrm{Al}_{2} \mathrm{O}_{3}$. 


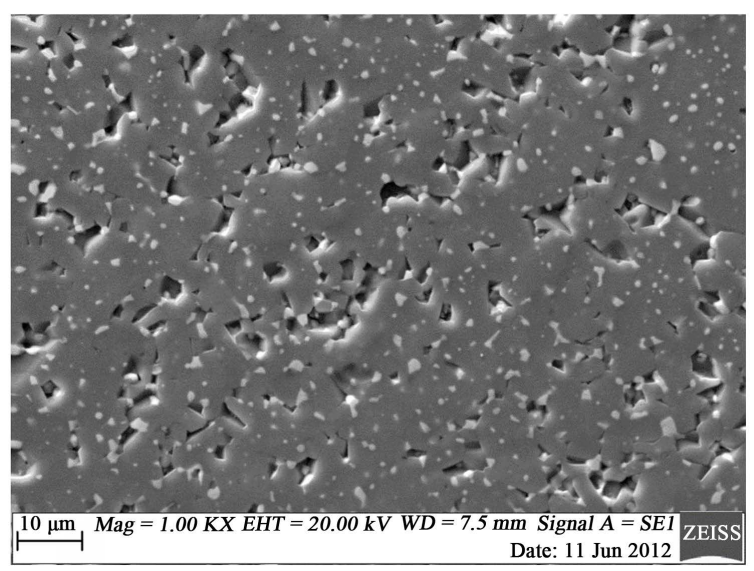

(a)

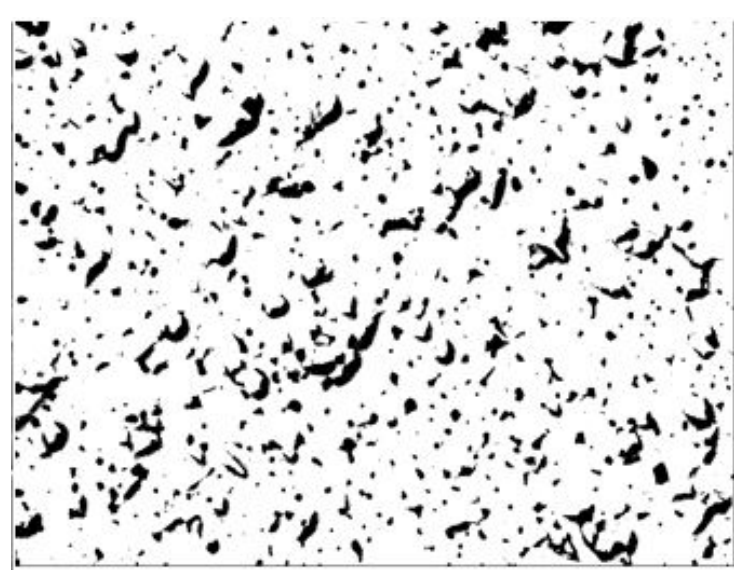

(b)

Figure 3. (a) SEM of polished sample surface on X 1000 showing the high level of porosity; and (b) porosity contrast (dark) producedby the image $\mathrm{J}$ analysis of (a).

HARDNESS-LOAD

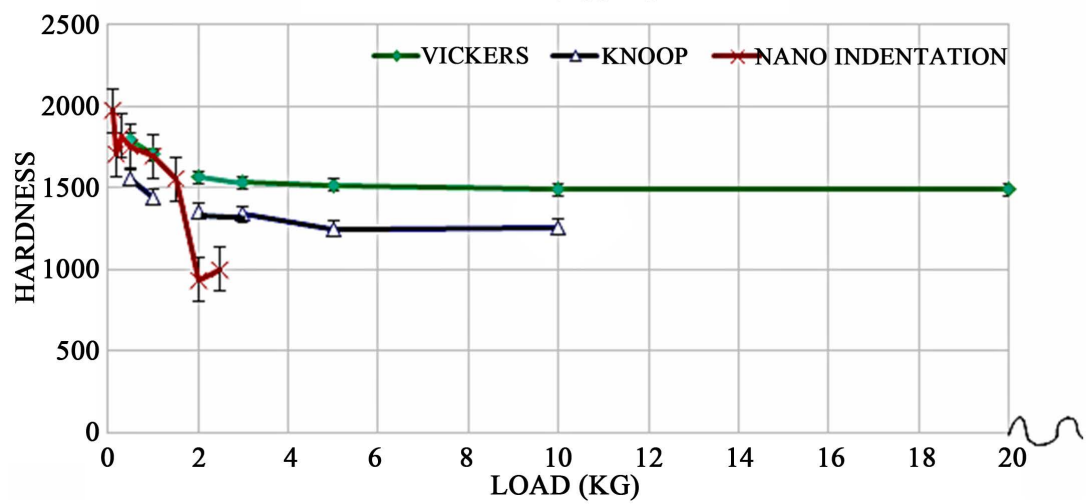

Figure 4. Hardness-load graph for the three indentation methods.

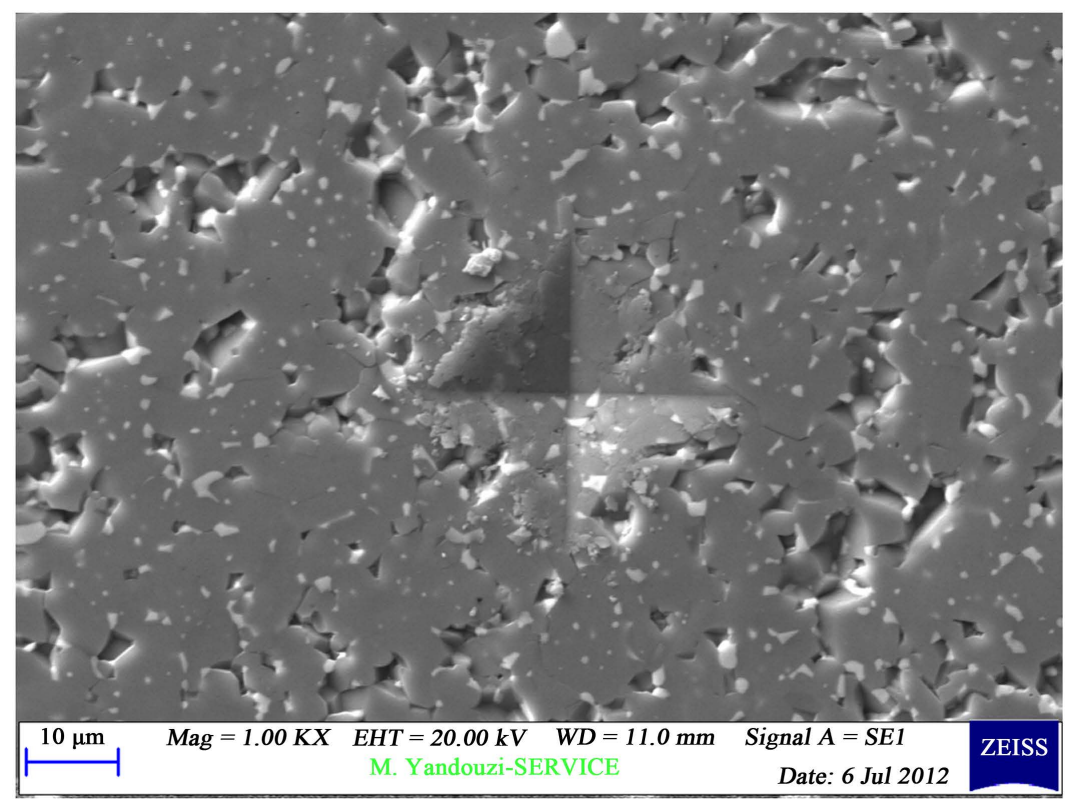

(a) 


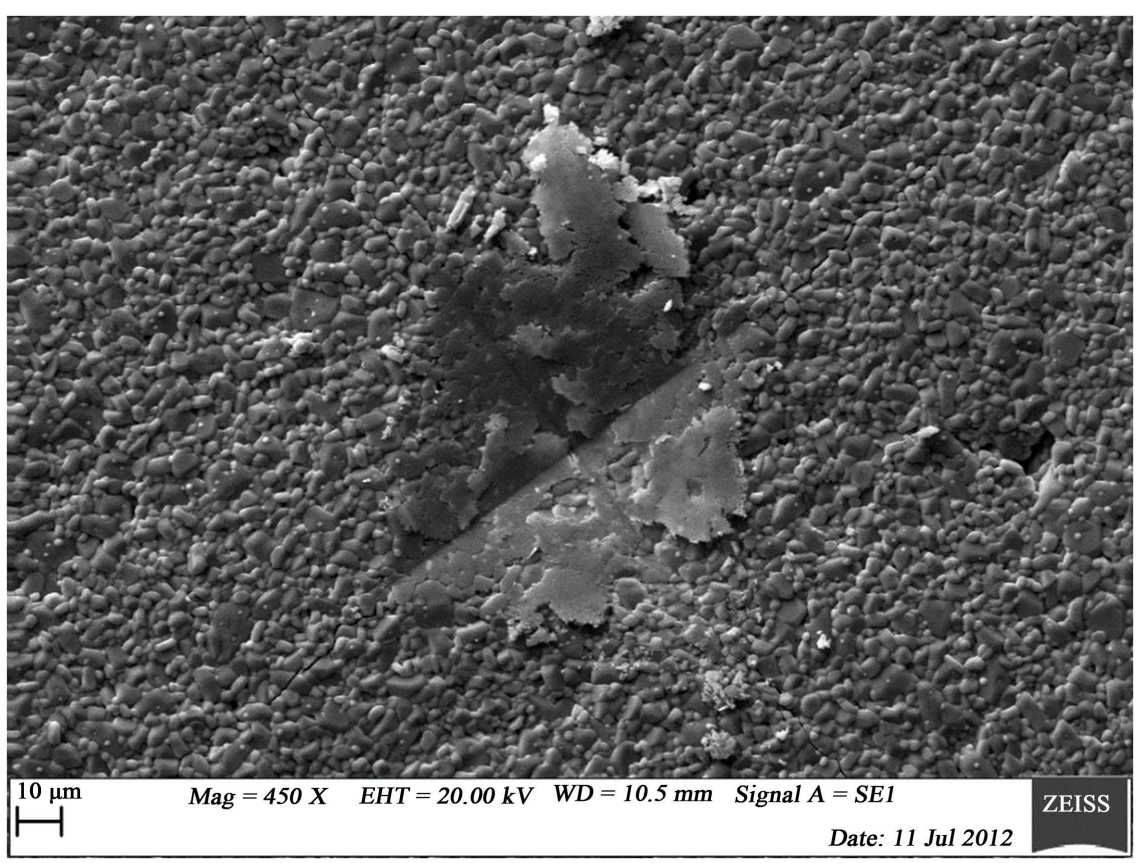

(b)

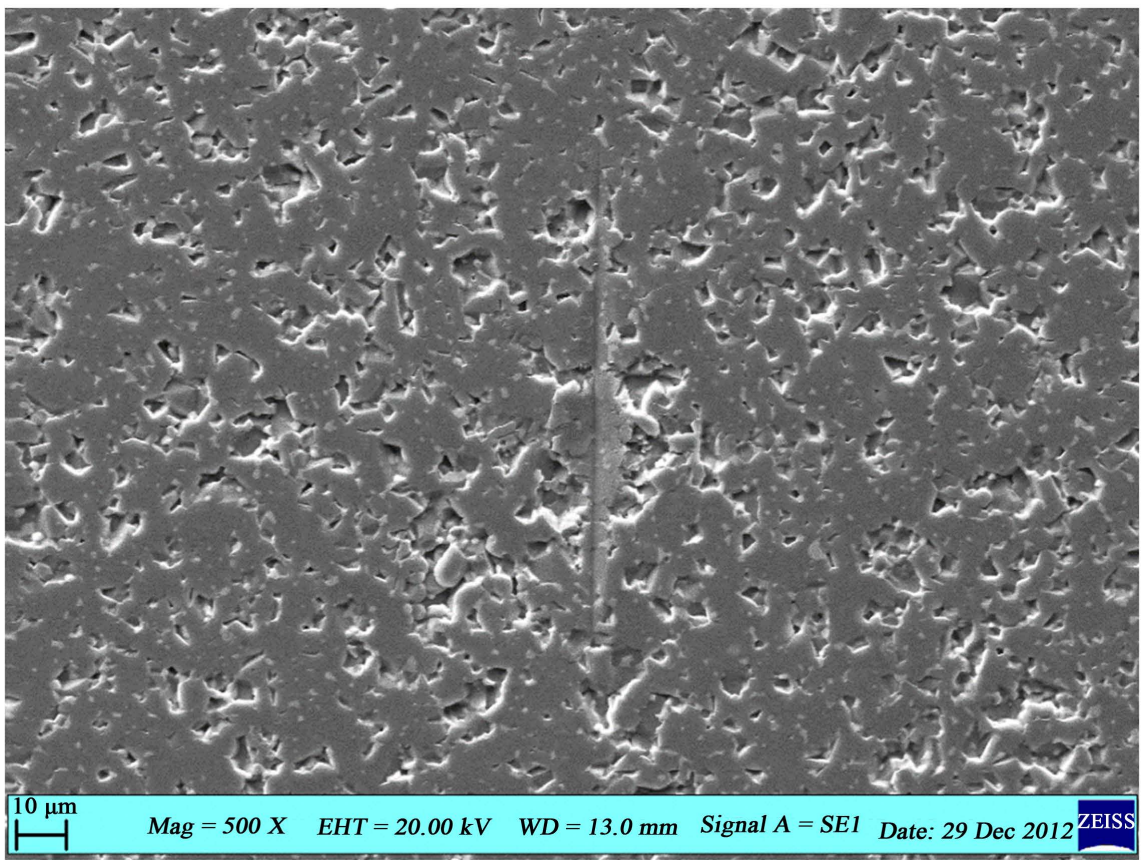

(c)

Figure 5. Low loads indents following (a) and (b) Vickers hardness; and (c) Knoop hardness testing.

Table 2. Hardness data.

\begin{tabular}{ccccccccccccccccc}
\hline Load (Kgf) & 0.1 & 0.2 & 0.3 & 0.5 & 1 & 1.5 & 2 & 2.5 & 3 & 5 & 10 & 20 & 30 & 50 & Average \\
\hline Vickers & - & - & - & 1796 & 1702 & - & 1566 & - & 1530 & 1516 & 1491 & 1491 & 1461 & 1511 & 1509 \\
Knoop & - & - & - & 1560 & 1440 & - & 1353 & - & 1337 & 1250 & 1259 & - & - & - & 1345 \\
Nano & 1975 & 1705 & 1818 & 1752 & 1695 & 1553 & 938 & 999 & - & - & - & - & - & - & 1387 \\
\hline
\end{tabular}


dentation size effect include the indenter/specimen friction, the elastic/plastic deformation response of the material and the high porosity in ZTA [13]. The load independent value of $1509 \mathrm{HV}$ was used as the characteristic hardness of this material.

Similar to the Vickers hardness, the Knoop hardness shows a strong load-hardness dependency, indicating an accentuated ISE phenomenon. The evaluated hardness value equals $1345 \mathrm{HK}$. The nanoindentation results fluctuate around $1800 \mathrm{HV}$ below $5 \mathrm{~N}$ showing a certain level of repeatability under low loads [14]. At higher loads however, a strong load dependency can also be recognised. An average nanohardness value of $1387 \mathrm{HV}$ with a coefficient of variance of $28.12 \%$ was calculated within the load range of up to $25 \mathrm{~N}$. The theoretical Vickers hardness can be calculated using the rule of mixture and hardness values of fully dense $\mathrm{Al}_{2} \mathrm{O}_{3}$ and $\mathrm{ZrO}_{2}$ and can be expected to range from 16 - $17 \mathrm{GPa}$ whereas the actual hardness was measured to be $14.89 \mathrm{GPa}$. This implies a 7.5\% drop with respect to the lower range of the theoretical value. The reason for this drop may be attributed to the average grain size of $5 \mu \mathrm{m}$, which is larger than what is commonly reported in literature [15] and the relatively high porosity level, which is in agreement with literature [16]. In summary, the wide distribution of hardness values can be attributed to the variations in porosity, grain structure and $\mathrm{ZrO}_{2}$ particle structure.

The hardness has so far been used as the primary selection criterion for armour ceramics [17] and is often directly compared to the hardness of the projectile to be defeated. Common projectile cores are made of hard steel and WC with hardness values ranging from 600 - $920 \mathrm{HV}$ to 1250 - $1500 \mathrm{HV}$, respectively [18]. Therefore, it can be seen that ZTA is strongly adequate for defeating hard steel core projectiles, but barely meets the requirements for defeating WC core threats.

\subsubsection{Fracture Toughness and Fracture Mode}

Well-formed visible cracks started at loads of $10 \mathrm{~kg}$. Presented in Figure 6(a) is an image of one of the cracks formed on the indent illustrating the measurement of the parameters $\mathrm{c}$ and a. The summary of the measured a, $\mathrm{c}$ and c/a values is presented in Table 3 and the plots of c, a, and c/a versus loads are presented in Figure 6(b). This study suggests that ZTA exhibits median type cracks with c/a ratios between 2.50 and 2.71, just above the value of 2.5 known to mark the transition from radial to median type cracking. Therefore, fracture toughness values calculated using the semi-empirical Equation (2) by Lawn et al. are in good agreement with toughness values measured using standard methods in this study and in literature [7].

The measured experimental $\mathrm{K}_{\mathrm{IC}}$ value of $4.90 \mathrm{MPam}^{1 / 2}$ is in agreement with the study conducted by Ganesh et al. [15] where $0-20 \mathrm{vol} \% \mathrm{ZrO}_{2}$ was used in the alumina matrix. This is well corroborated by the measured Charpy impact toughness of $0.34 \mathrm{~J}$ [10]. Comparing the measured toughness value to that of monolithic alumina with a toughness of about $2.69 \mathrm{MPam}^{1 / 2}$ [19], ZTA shows an increase by $82.2 \%$. Moreover, residual stresses might also be created during indentation, which can accelerate crack growth and lead to an under-estimation of the materials toughness [20]. However, the radial crack length factor c is observed to remain a consistent function of the applied load and material properties. In fact, the $\mathrm{c}^{3 / 2}$ versus indentation load plot shown in Figure 7(a) indicates a good linear dependence in agreement with previous work by Lee et al. [21].

The mechanism of toughening by $\mathrm{ZrO}_{2}$ is predominantly governed by its particle size. In this study, three toughening mechanisms are found to account for the $\mathrm{K}_{\mathrm{IC}}$ increase. Firstly, the stress-induced tetragonal-to-monoclinic phase transformation where the size of $\mathrm{ZrO}_{2}$ particle is predominantly below $1 \mu \mathrm{m}$ [22], leading to a volume increase by about $4 \%$ [6]. The volume increase has the tendency to close growing cracks, thereby impeding crack growth leading to an increase in $\mathrm{K}_{\mathrm{IC}}$. Secondly, the grain size of the alumina $(5-10 \mu \mathrm{m})$ with an aspect ratio of 2 contributes to crack deflection and crack bridging. In addition, mechanical loading was observed to cause local plastic deformation, pore collapse and densification which promotes local further energy absorption and retards the initiation of large fracture causing cracks.

Table 3. Measured crack size [10].

\begin{tabular}{|c|c|c|c|c|c|}
\hline \multicolumn{2}{|c|}{ Load (kgf) } & \multirow{2}{*}{$\begin{array}{c}10 \\
56.3\end{array}$} & \multirow{2}{*}{$\begin{array}{c}20 \\
77.6\end{array}$} & \multirow{2}{*}{$\begin{array}{c}30 \\
97.5\end{array}$} & \multirow{2}{*}{$\begin{array}{c}50 \\
124.5\end{array}$} \\
\hline & $\mathrm{a}$ & & & & \\
\hline \multirow[t]{2}{*}{ Crack parameters } & C & 148.2 & 210.4 & 243.3 & 327.3 \\
\hline & $\mathrm{c} / \mathrm{a}$ & 2.63 & 2.71 & 2.50 & 2.63 \\
\hline
\end{tabular}




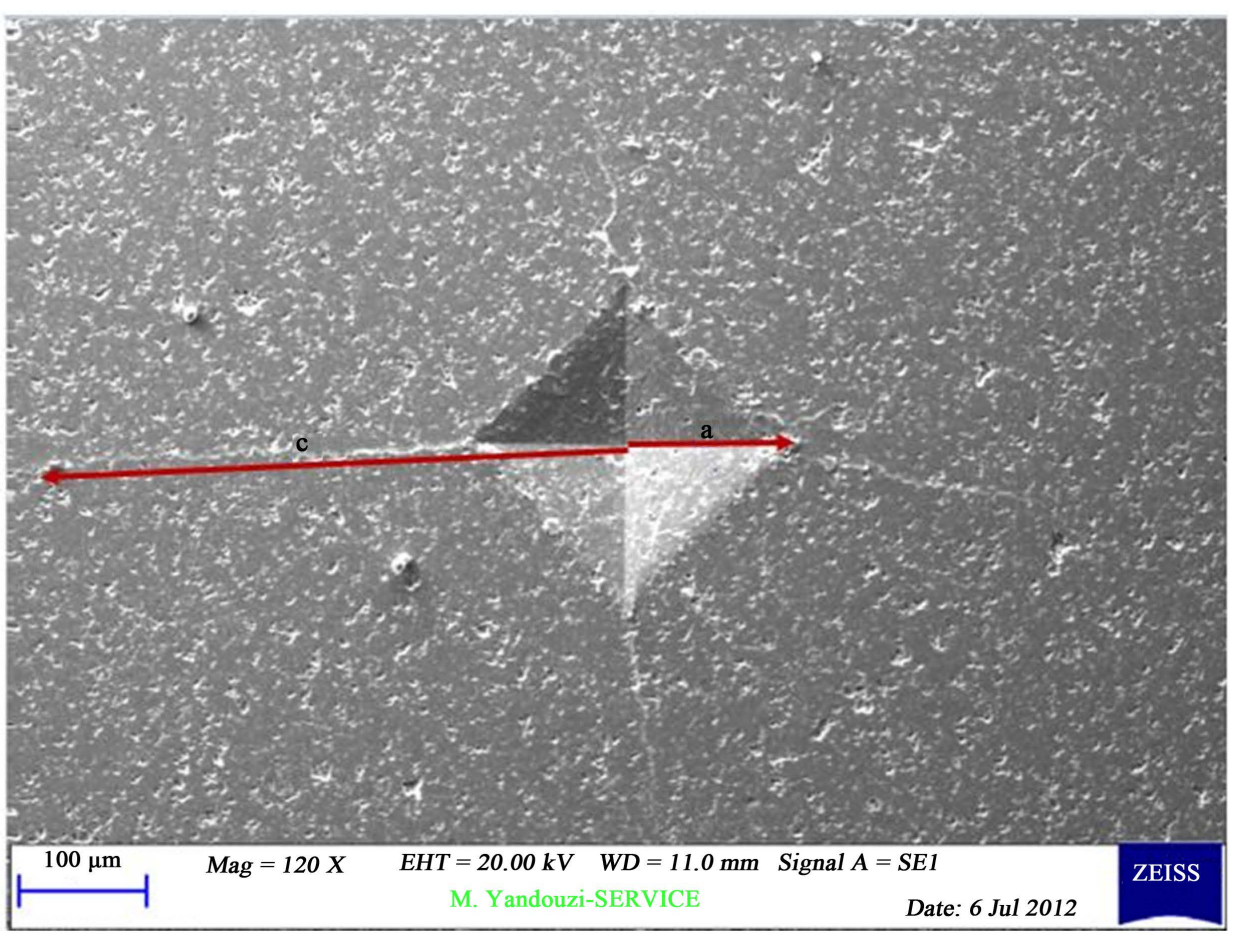

(a)

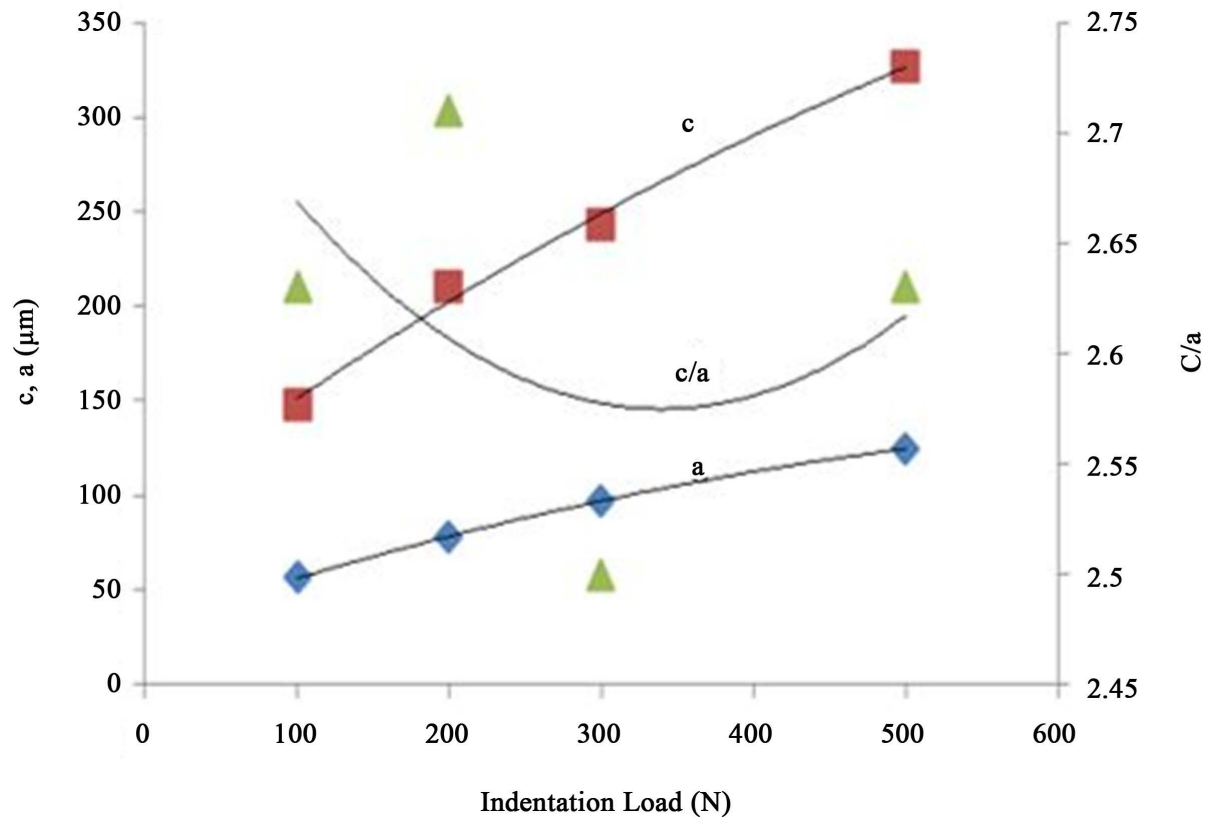

(b)

Figure 6. (a) SEM images showing Vickers indents and radial cracks. The arrows illustrate the measurement of the crack size parameters a and c; and (b) a, c and c/a ratios as a function of indentation load.

The crack growth path and fracture mode are presented in the SEM images of Figure 8(a) and Figure 8(b). They reveal evidence of predominantly intergranular fracture. Previous studies have shown that the intergranular failure mode on low porosity material, as found in this study, has great potential for energy absorption during fracture [23]. 


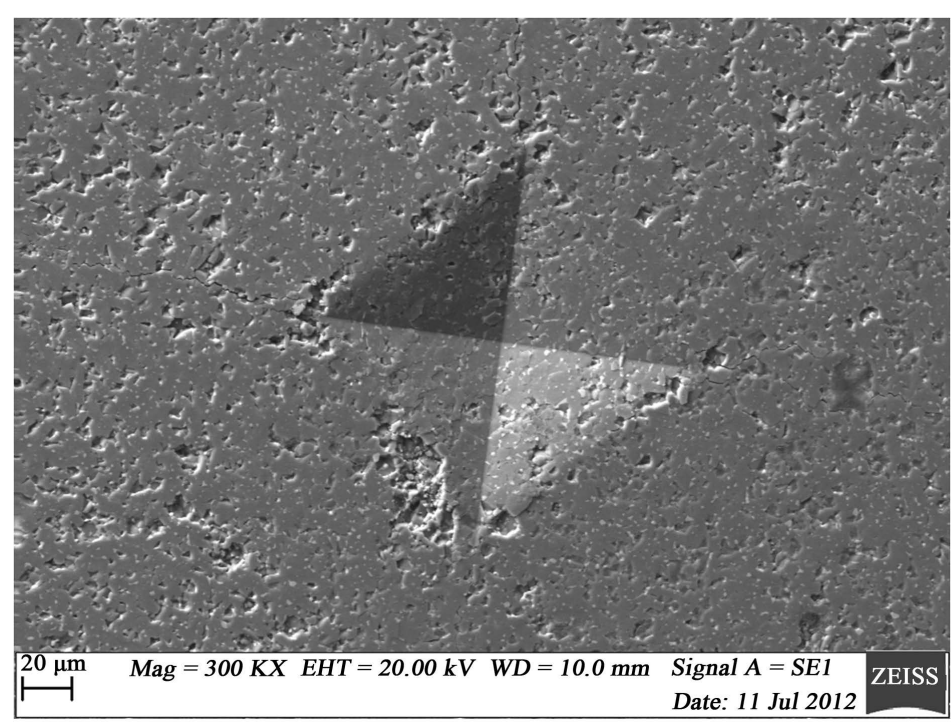

(a)

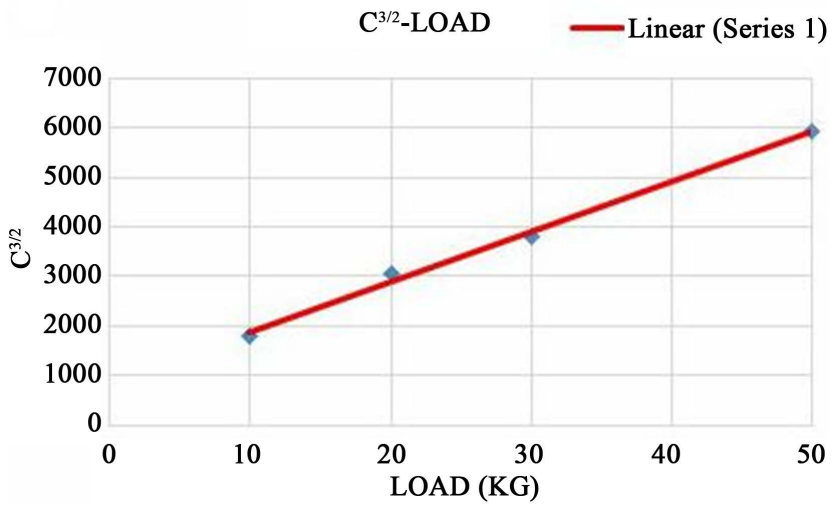

(b)

Figure 7. (a) Relationship between crack length c and indentation load; (b) SEM image of Vickers indent under $30 \mathrm{~kg}$ load showing pore collapse and densification during loading.

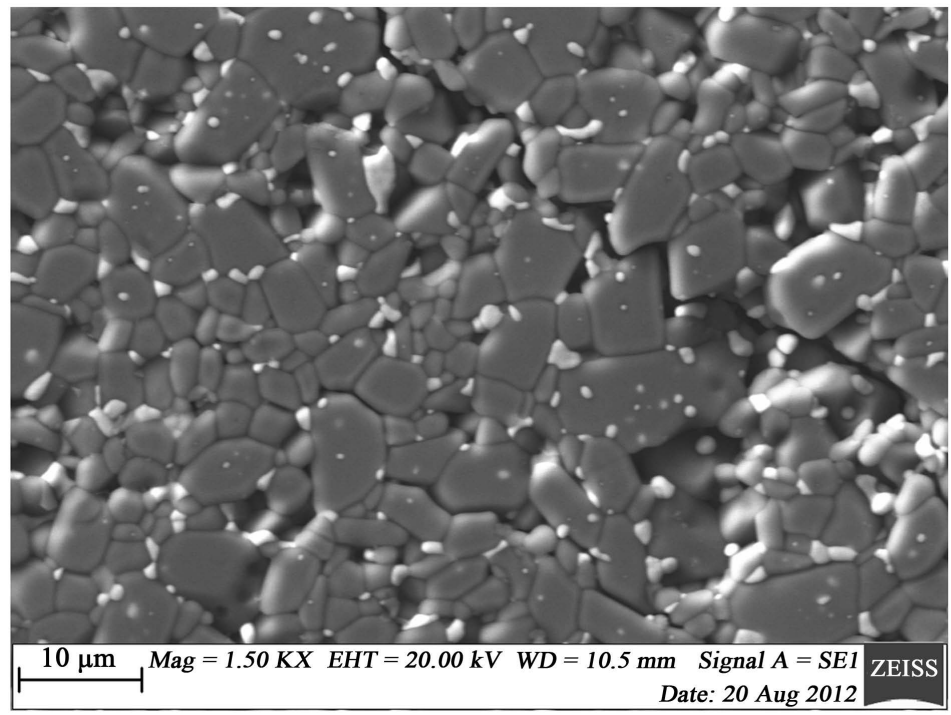

(a) 


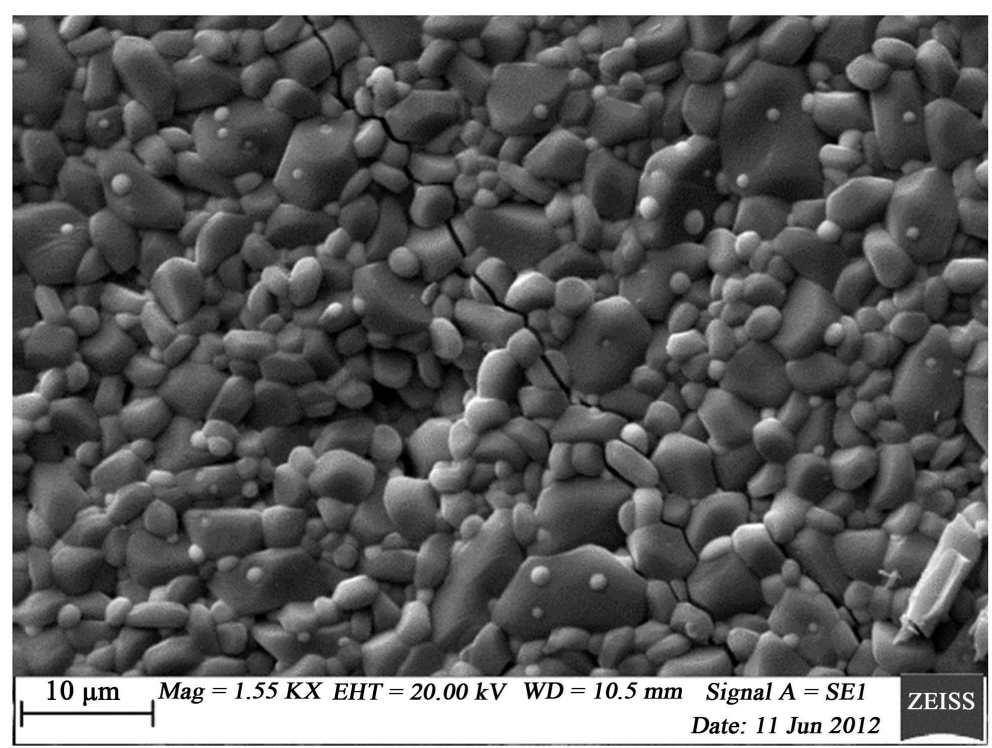

(b)

Figure 8. SEM images of the material showing predominantly an intergranular mode of failure: (a) etched specimen; (b) unpolished surface.

\subsubsection{Strength}

Presented on Table 4 are the results of the ring-on-ring (RoR) test, evaluated using Equation (5). The recorded average strength value is 184.4 MPa. Figure 9(b) shows image of the fractured RoR test samples. It is evident that the fracture originated in the maximum stress region within the loading ring, thereby confirming the test validity according to the standard. The fracture is typical for low crack density failure with exclusively primary crack patterns resulting into only 5 to 7 fragments (Figure 9(b) and Figure 9(c)). Microscopy revealed a primarily intergranular mode of failure as shown in Figure 8 above. The observed small number of fragments indicate high fracture toughness, high fraction of energy absorption by deformation, and low fraction of energy absorption by fracture surface formation. Moreover, the low fragment density is characteristic of a lower amount of elastic energy under load that would need to be released upon fracture.

$$
\begin{gathered}
\sigma_{f}=\frac{3 F}{2 \pi h^{2}}(1-v) \frac{\left(D_{s}^{2}-D_{L}^{2}\right)}{2 D^{2}}+(1+v) \ln \frac{D_{s}}{D_{L}} \\
D=\frac{L}{0.90961+0.12652 \frac{h}{D_{s}}+0.000168} \ln \frac{l-D_{s}}{h}
\end{gathered}
$$

where $h$ and $l$ are the thickness and length of the square plates, respectively; $L$ is $0.5(l+l)$; the equivalent sample diameter $(D)$ is calculated using Equation (6); $D_{s}$ is the supporting ring diameter $=50 \mathrm{~mm} ; D_{L}$ is the loading ring diameter $=25 \mathrm{~mm}$ and $v$ is the Poisson ratios $=0.21$. The modulus of elasticity is taken to be $330 \mathrm{MPa}$.

Table 5 shows the results of the four-point bend test. An average flexural strength of $292 \mathrm{MPa}$ was calculated, which is $58.4 \%$ higher than the RoR strength determined from ring-on-ring tests. This difference is expected from earlier literature observations [24] and can be rationalised by the larger material test volume involved in RoR tests that statistically increases the likelihood of larger defects resulting in larger stress concentration and earlier fracture. Overall however, it must be noted that the RoR strength value might also be under-estimated due to sub-critical crack growth [22]. Therefore, the uniaxial 4 point bend strength of $292 \mathrm{MPa}$ is adopted in this study as custom in literature with respect to the fracture strength of ceramics.

The measured four-point bend strength of ZTA is $16.6 \%$ lower compared to the uniaxial strength value of 350 MPa reported in literature [25]. This difference can be rationalised by the fact that the fracture strength of ceramic materials is primarily governed by flaws. Therefore, the Griffith mechanics theory of fracture given by Equation (7) [26] was applied. In this equation, the key independent factor is the critical size of flaws, which is 


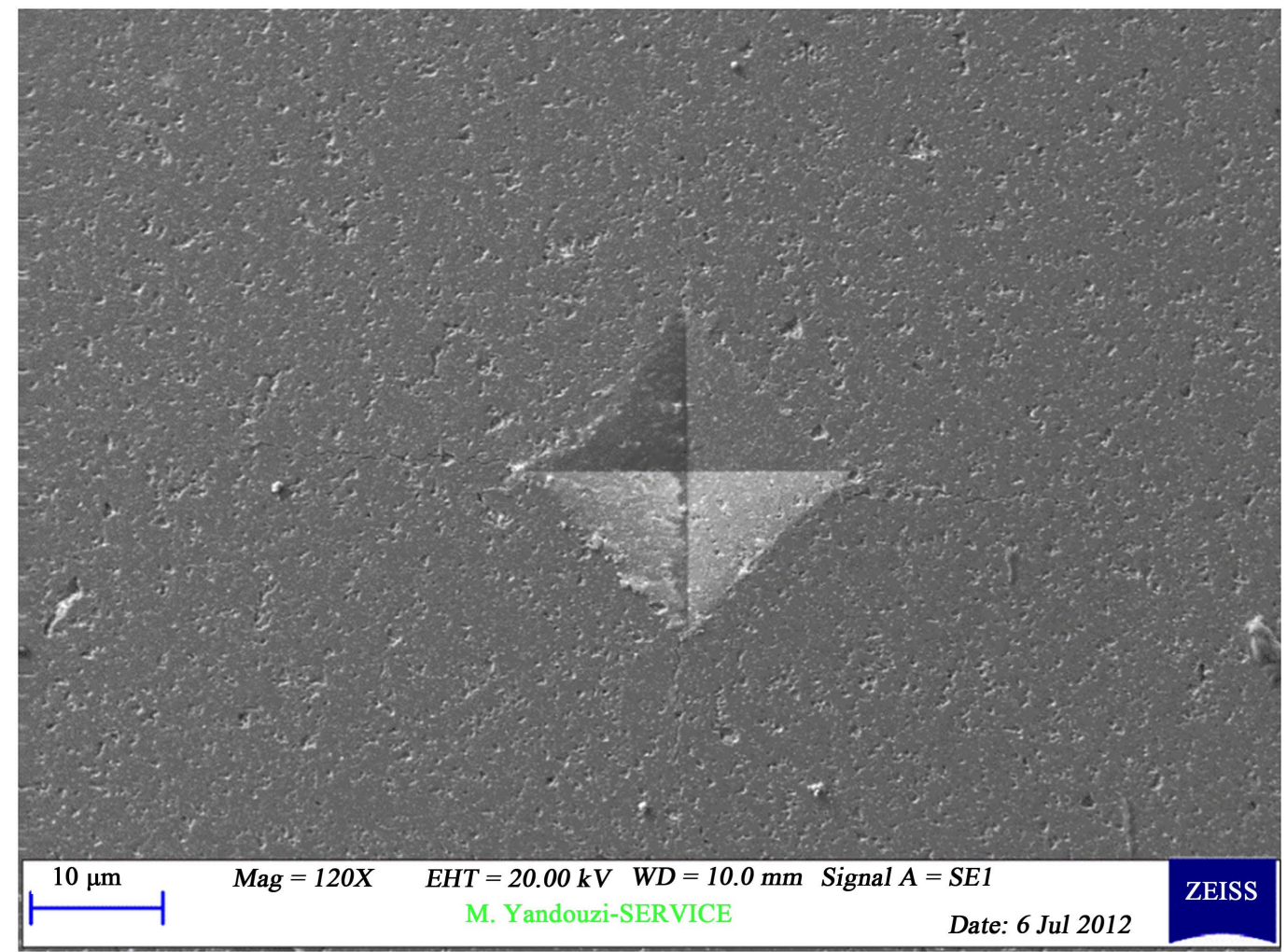

(a)

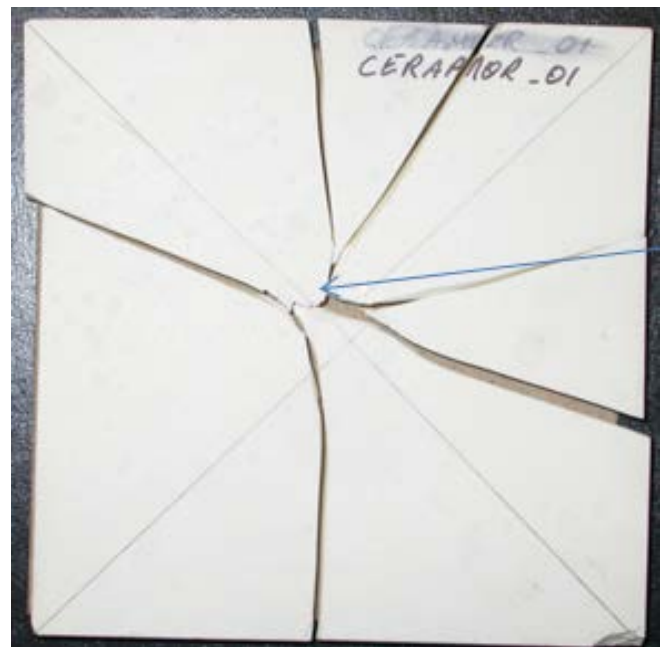

(b)

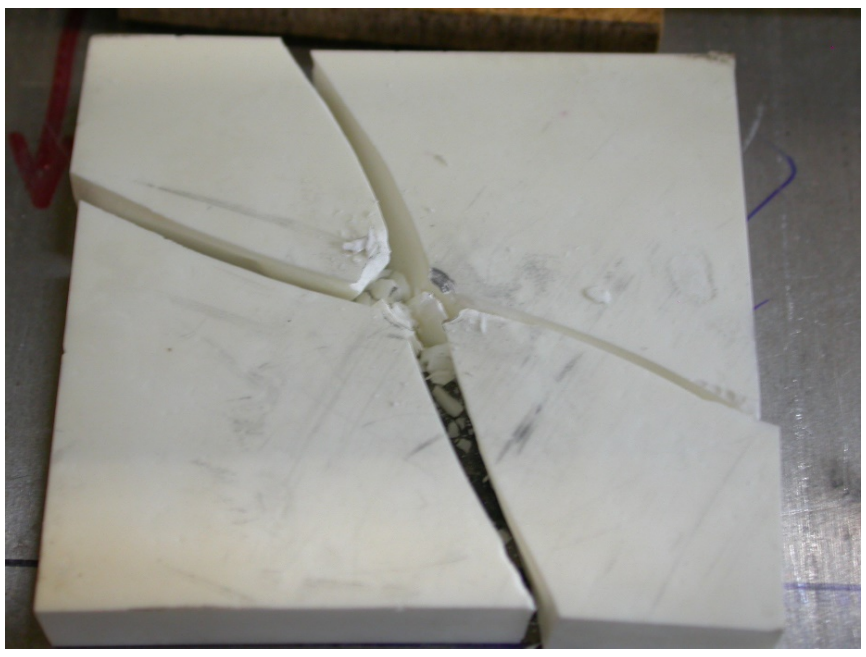

(c)

Figure 9. Fracture resistance and behaviour of ZTA: (a) $50 \mathrm{~kg}$ load Vickers indent; (b) photograph of RoR failed specimen; (c) photograph of failed drop tower test with $60 \mathrm{~mm}$ drop height.

Table 4. Test data, material parameters and strength of the material through ring-on-ring test.

\begin{tabular}{ccccccccc}
\hline Specimen & Max. load $(\mathrm{N})$ & $\mathrm{H}(\mathrm{mm})$ & $\mathrm{L}(\mathrm{mm})$ & $\mathrm{D}(\mathrm{mm})$ & $\sigma_{\mathrm{f}}(\mathrm{MPa})$ & $\sigma_{\text {fmean }}(\mathrm{MPa})$ & Standard deviation & \% Coefficient variation \\
\hline ZTA 01 & 22711 & 6.871 & 101.27 & 109.20 & 206.9 & & & 11.9 \\
ZTA 02 & 17877 & 6.863 & 101.25 & 109.20 & 163.2 & 184.4 & 21.9 & \\
ZTA 03 & 19949 & 6.905 & 101.36 & 109.25 & 179.9 & & & \\
\hline
\end{tabular}


Table 5. Four-point bend test result.

\begin{tabular}{ccccc}
\hline Material & $\begin{array}{c}\text { Load at } \\
\text { fracture }(\mathrm{N})\end{array}$ & $\begin{array}{c}\text { Flexural strength } \\
\left(S=\frac{3 P L}{4 b d^{2}}\right)\end{array}$ & $\begin{array}{c}\sigma_{\text {mean }}(\mathrm{MPa}) \\
\text { Standard } \\
\text { deviation }\end{array}$ & $\begin{array}{c}\text { \% Coefficient } \\
\text { variation }\end{array}$ \\
\hline ZTA 01 & 295.43 & 270.16 & & \\
02 & 266.89 & 318.27 & 292.56 & \\
03 & 415.79 & 326.29 & & \\
04 & 440.61 & 272.79 & & \\
05 & 396.79 & 293.48 & & \\
07 & 459.23 & 273.62 & & \\
\hline
\end{tabular}

$\mathrm{P}$ is the load at fracture; $\mathrm{L}$ is the span; and $\mathrm{b}$ and $\mathrm{d}$ are specimen rectangular cross-section dimensions $4 \mathrm{~mm}$ and $3 \mathrm{~mm}$, respectively.

referred to as failure-causing crack (FC).

$$
\sigma_{a}=\frac{K_{i c}}{Y \sqrt{\pi a}}
$$

where $\sigma_{a}$ is the applied stress; $K_{I C}$ is the fracture toughness; $a$ is the half crack length; and $Y$ is the pore shape factor.

Solving Equation (7) for a, a critical flaw size of $173 \mu \mathrm{m}$ was determined suggesting that multiple pores may coalesce to cause the final fracture of the material. Overall however, the observed relatively high porosity of $10.5 \%$ seems to be compensated by the presence of zirconia particles at grain boundaries [27] resulting in substantial toughening by crack deviation that leads to higher energy absorption during fracture. Therefore, the strength value of $292 \mathrm{MPa}$ may be viewed as appropriate for the ballistic performance of ZTA considering its resistance to cracking in both RoR and drop weight tests. The adequacy of the ZTA strength for ballistic performance despite its high porosity is also stated in the literature [16]. Moreover, ZTA samples showed the ability to sustain loads as high as $50 \mathrm{~kg}$, as shown in Figure 9(a), and exhibited a strong deformation resistance as confirmed during the Vickers indentation tests, all of which are indications for potentially good ballistic performance.

\subsubsection{Drop Weight Test}

Table 6 summarizes the results of the drop tower test. From this table, the transition from non-fractured to fractured samples can be found to have occurred at a drop height of $40 \mathrm{~mm}$ to $50 \mathrm{~mm}$. However, other important parameters such as impact energy, impact velocity and total energy do not follow this pattern, especially in the $60 \mathrm{~mm}$ height test. This may be due to the influence of frictions in the machine and/or to residual stresses during specimen preparation. While a drop height of $50 \mathrm{~mm}$ causes a crack to form at the front surface (designated as the strike surface), the cracks do not propagate through the entire thickness to the back surface. However, at a drop height of $60 \mathrm{~mm}$, the test plates break completely into four fragments, as shown in Figure 9(c). This relatively small number of fragments is an indication of considerable energy absorption capability confirming the adequacy of the strength and fracture toughness of ZTA.

\subsubsection{Density}

A contrast image from the ultrasonic test is presented in Figure 10 [10]. It shall be noted that the apparent density gradients may instead reflect thickness variations within the test plates leading to variations in sound path length and sound travel duration [28]. The relationship between the effective density ( $\rho$ ) and the porosity (P) is given by Equation (4).

The theoretical density $\rho_{0}$ is estimated using the rule of mixture and the theoretical densities of $\mathrm{ZrO}_{2}$ and $\mathrm{Al}_{2} \mathrm{O}_{3}$, which are 6.1 and $3.98 \mathrm{~g} / \mathrm{cm}^{3}$, respectively. Considering the respective volume percentages of $85.4 \%$ and $12.9 \%$ of alumina and zirconia as measured using SEM/EDS, the theoretical density $\rho_{0}$ of ZTA is calculated to be $4.15 \mathrm{~g} / \mathrm{cm}^{3}$ [10]. Density measurements using the Archimedes and porosity methods produced density values 


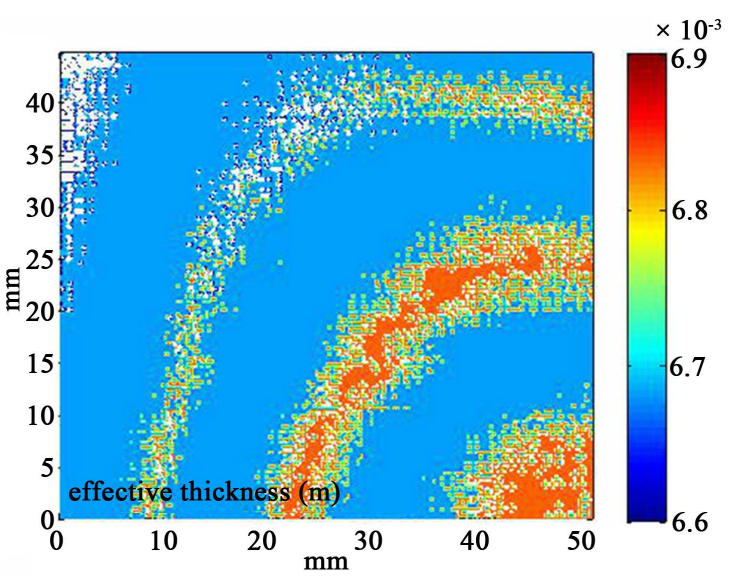

(a)

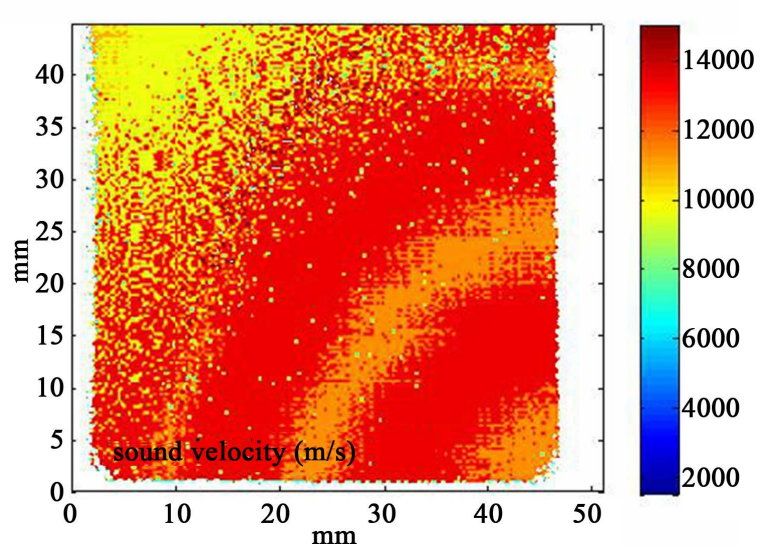

(b)

Figure 10. Ultrasonic tests on the ceramic test plates. The centre of the plate is at the lower right corner of the images: (a) effective plate thickness; (b) sound velocity [10].

Table 6. Drop weight test result.

\begin{tabular}{cccccccc}
\hline Material & Drop height $(\mathrm{mm})$ & Load $(\mathrm{N})$ & Impact energy $(\mathrm{J})$ & Impact velocity $(\mathrm{m} / \mathrm{s})$ & Total energy $(\mathrm{J})$ & Fracture \\
\hline ZTA-1 & 60 & 9039.6 & 2.0165 & 0.8955 & 0.8263 & Yes \\
ZTA-2 (S) & 50 & 9759.2 & 2.5703 & 1.0110 & 1.9695 & Yes \\
ZTA-3 (B) & 50 & 10567.5 & 2.5864 & 1.0142 & 0.9966 & No \\
ZTA-4 (S) & 50 & 9325.8 & 2.5896 & 1.0148 & 1.7043 & Yes \\
ZTA-5 (B) & 50 & 10425.7 & 2.5985 & 1.0165 & 0.9663 & No \\
ZTA-6 & 40 & 6523.3 & 2.9932 & 1.0910 & 1.4220 & No \\
\hline
\end{tabular}

Where $\mathrm{S}$ stands for the strike patterned face; B stands for the back surface and the drop weight for each test was $5.0292 \mathrm{~kg}$.

of $3.78 \mathrm{~g} / \mathrm{cm}^{3}$ and $3.75 \mathrm{~g} / \mathrm{cm}^{3}$, respectively, in agreement with the work of Zhang and Li [16]. Comparing these measured values to the estimated theoretical density of $4.15 \mathrm{~g} / \mathrm{cm}^{3}$ translates into a $8.9 \%$ drop to a relative density of $91.1 \%$. The high level of porosity in ZTA is a result of the grains mismatch between the initial constituents $\mathrm{ZrO}_{2}$ and $\mathrm{Al}_{2} \mathrm{O}_{3}$, which persists at the interface, even after sintering [16].

\subsubsection{Young's Modulus}

The strong correlation between porosity and Young's modulus allows the use of semi-empirical Equation (3) [29] to calculate the Young's Modulus. This equation is adopted from the work of Deng et al. [8] and was used to simulate the compactness of ZTA by solving for the parameter $b$ determined to be equal to 2 . This value is an indication that the pores are not spherical or compact, as confirmed in Figure 11 that shows pores with complex shapes along grain boundaries and grain triple points. Using Equation (3) and a porosity value of $10.5 \%$, the modulus of elasticity was estimated at $272 \mathrm{GPa}$. For this calculation, the pore free modulus of elasticity is taken to be 360 , as determined using the rule of mixture. An alternative method used to estimate the modulus of elasticity is the instrumented indentation hardness test. Under this test, the modulus is determined using the slope of the load versus indentation depth below $3 \mathrm{~N}$ in the elastic region, as established by the Oliver-Pharr method [6] [30]. The results are summarized in Table 7, giving an average value of 306 GPa.

\subsection{General Discussion on the Impact of Toughening and Other Properties to Ballistic Performance}

A thorough review of toughening mechanisms in carbon nanotube reinforced ceramic matrix composites is provided by the work of Samal and Bal [2]. In this study, it was reported that zirconia particles strengthen alumina 


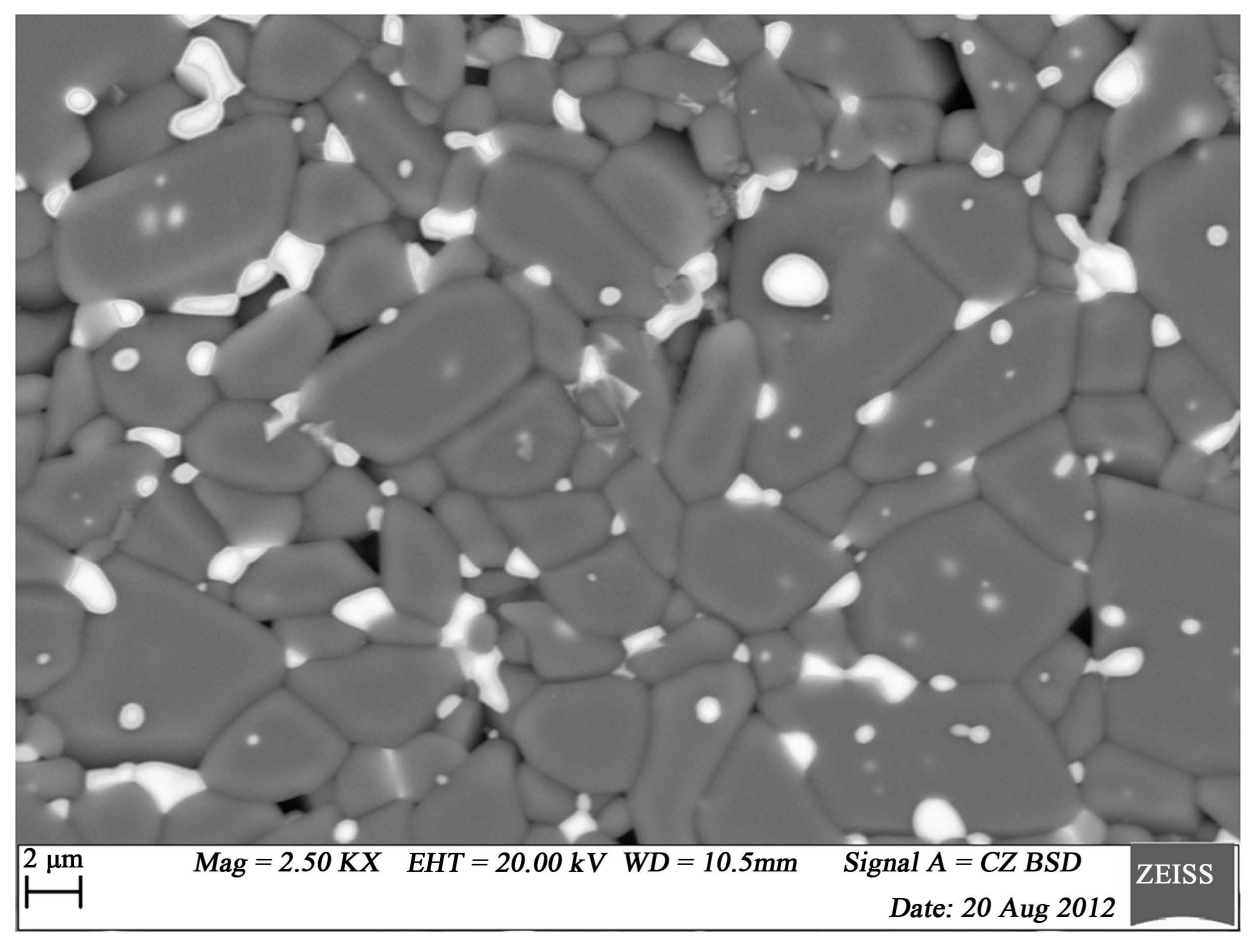

Figure 11. SEM of etched samples showing the grain structure.

Table 7. Young's modulus data.

\begin{tabular}{cccccccccc}
\hline Load (N) & 1 & 2 & 3 & 5 & 10 & 15 & 20 & 25 & $E_{\text {average }}$ \\
\hline E (GPa) & 334 & 279 & 304 & 270 & 232 & 191 & 180 & 235 & 306 \\
\hline
\end{tabular}

by both grain pining and refinement during fabrication as well as fracture resistance during failure [31]. The level of toughening was found to depend on volume fraction, size and distribution of zirconia particles within the alumina matrix. Toughening mechanisms in ZTA include tetragonal-to-monoclinic phase transformation in the $\mathrm{ZrO}_{2}$ particles, crack deflection and bridging, as well as energy absorption by plastic deformation, pore collapse and densification. This explains the coarse fragmentation illustrated in Figure 9. Overall, mechanical properties measured in this study on ZTA are within specification ranges for $7.62 \times 51$ AP level IV, $4068 \mathrm{~J}$ threats [32], which is encouraging for future ballistic performance. It shall be noted that in addition to improved fracture toughness and strength, microstructure and other armour related mechanical properties also significantly influence ceramics fragmentation during ballistic events [33].

Although pores are generally recognised as detrimental to the strength of ceramics, it has been proven that uniformly distributed small-size pores can indeed provide good ballistic performance [34]. In fact, thanks to energy absorption by local pore collapse and densification, pores can retard the initiation of relatively large fracture causing cracks making them potentially beneficial to the residual strength of ceramics [33], which is recognised as an important factor for enhanced ballistic performance and multi-hit capability [35]. Other properties that are known to enhance the armour ceramics performance include the hardness, Young's modulus, sonic velocity and grain size.

Furthermore, the improvement of multi-hit capability of ceramics as a function of increased fracture toughness has been studied through depth of penetration tests. In a comparative study [3], Savio et al. found the fracture strength of ZTA and alumina to be 274 and $272 \mathrm{MPa}$, respectively, while their hardness under $0.2 \mathrm{~kg}$ indentation load was 1790 and $1780 \mathrm{HV}$, respectively. The study concluded that ZTA outperformed alumina because of its greater fracture toughness, as modest as the difference may seem. Also, a numerical study showed that the ballistic resistance of ZTA was better than that of AD 95 alumina due to increased $\mathrm{K}_{\mathrm{IC}}$ in ZTA that also exhibited hardness and strength values of $1796 \mathrm{HV}$ and $292 \mathrm{MPa}$, respectively [4]. 


\section{Conclusion}

In this work, the properties of ZTA have been investigated. It was demonstrated that: 1) a synergistic combination of toughening mechanisms including phase transformation in $\mathrm{ZrO}_{2}$ particles, crack deflection and bridging, plastic deformation, local pore collapse and densification, is crucial in achieving a substantial increase in fracture toughness; 2) A reduction in flaws in terms of defect volume fraction, size and distribution is also key for preserving efficient toughening; 3) The relatively high fracture toughness of ZTA compared to common monolithic ceramics such as alumina makes it a promising material for ballistic body protection. This high fracture toughness combined with other optimised armour related properties, such as hardness, strength and Young's modulus, can be key for improving the fragmentation behaviour and the multi-hit capability in ceramic armours.

\section{Acknowledgements}

The authors would like to thank the Defence R \& D Canada (DRDC Valcartier), Quebec, Canada for providing the material and creating an enabling working environment, as well as the National Research Council Canada, NRC Aerospace, Ottawa, Canada for allowing the use of their facilities for the experimental work.

\section{References}

[1] Medvedovski, E. (2010) Ballistic Performance of Armour Ceramics: Influence of Design and Structure. Part 1. Journal of Ceramics International, 36, 2103-2115. http://dx.doi.org/10.1016/j.ceramint.2010.05.021

[2] Samal, S.S. and Bal, S. (2008) Carbon Nanotube Reinforced Ceramic Matrix Composites-A Review. Journal of Minerals and Materials Characterisation \& Engineering, 7, 355-370. http://dx.doi.org/10.4236/jmmce.2008.74028

[3] Savio, S.G., Madhu, V. and Gogia, A.K. (2014) Ballistic Performance of Alumina and Zirconia-Toughened Alumina against 7.62 Armour Piercing Projectile. Defence of Science Journal, 64, 477-483. http://dx.doi.org/10.14429/dsj.64.6745

[4] Ren, H.L., Chen, W. and Guo, T.T. (2013) Numerical Simulation on Anti-Penetration Properties of the Ceramic Target. Beijing LigongDaxueXueba/Transaction of Beijing Institute of Technology, 33, 111-115.

[5] Woodward, R.L., Gooch Jr., W.A. O’Donnell, R.G., PerciBalli, W.J., Baxter, B.J. and Pattie, S.D. (1994) A Study of Fragmentation in the Ballistic Impact of Ceramics. International Journal of Impact Engineering, 15, 605-618. http://dx.doi.org/10.1016/0734-743X(94)90122-2

[6] Nastic, A., Merati, A., Bielawski, M., Bolduc, M., Fakolujo, O. and Nganbe, M. (2015) Instrumented and Vickers Indentation for the Characterization of Stiffness, Hardness and Toughness of Zirconia Toughened $\mathrm{Al}_{2} \mathrm{O}_{3}$ and SiC Armor. Journal of Materials Science and Technology, 31, 773-783. http://dx.doi.org/10.1016/j.jmst.2015.06.005

[7] Rocha-Rangel, E. (2011) Fracture Toughness Determinations by Means of Indentation Fracture. In: Cuppoletti, J., Ed., Nanocomposites with Unique Properties and Applications in Medicine and Industry, 21-38. http://dx.doi.org/10.5772/18127

[8] Deng, H., Fukusawa, T., Ando, M., Zhang, G. and Ohji, T. (2001) Microstructure and Mechanical Properties of Porous Alumina Ceramics Fabricated by the Decomposition of Aluminum Hydroxide. Journal of American Ceramic Society, 84, 2638-2644. http://dx.doi.org/10.1111/j.1151-2916.2001.tb01065.x

[9] Asmani, M., Kermel, C., Leriche, A. and Qurak, M. (2001) Influence of Porosity on Young’s Modulus and Poisson’s Ratio in Alumina. Journal of European Ceramic Society, 21, 1081-1086. http://dx.doi.org/10.1016/S0955-2219(00)00314-9

[10] Fakolujo,O.S., Merati, A., Nganbe, M., Bielawski, M. and Bolduc, M. (2014) A study of Armour Related Properties of Ceramics. Ceramic Transaction, 249, 82-90. http://dx.doi.org/10.1002/9781118995433.ch9

[11] Ostrowski, T. and Rodel, J. (1999) Evolution of Mechanical Properties of Porous Alumina during Free Sintering and Hot Pressing. Journal of American Ceramic Society, 82, 3080-3086. http://dx.doi.org/10.1111/j.1151-2916.1999.tb02206.x

[12] Du, B., Zhao, B. and Duan, T. (2012) Influence of Zirconia Content and Grain Size on Physical and Mechanical Properties of ZTA Ceramics. Journal of Applied Mechanics and Materials, 143-144, 485-488. http://dx.doi.org/10.4028/www.scientific.net/AMM.143-144.485

[13] Sakai, M. (1993) Energy Principle of the Indentation-Induced Inelastic Surface Deformation and Hardness of Brittle Materials. Acta Metallurgica et Materialia, 41, 1751-1758. http://dx.doi.org/10.1016/0956-7151(93)90194-W

[14] Morrell, R. (2010) Effective Methods to Determine Hardness and Toughness of Structural Ceramics. Ceramic Transaction, 219, 355-362. http://dx.doi.org/10.1002/9780470917145.ch51 
[15] Ganesh, I., Sundararajan, G., Olhero, S.M. and Ferreira, J.M. (2011) Influence of Chemical Composition on Sintering Ability of ZTA Ceramic Consolidated from Freeze Dried Granules. Ceramics International, 37, 835-841. http://dx.doi.org/10.1016/j.ceramint.2010.10.027

[16] Zhang, X.F. and Li, Y.C. (2010) On the Comparison of the Ballistic Performance of $10 \%$ Zirconia Toughened Alumina and 95\% Alumina Ceramic Target. Journal of Materials \& Design, 31, 1945-1952. http://dx.doi.org/10.1016/j.matdes.2009.10.046

[17] Swab, J.J. (2004) Recommendations for Determining the Hardness of Armour Ceramics. Journal of Applied Ceramic Technology, 1, 219-225.

[18] Hazell, P.J. (2006) Ceramic Armour Design and Defeat Mechanics. Argos Press, Canberra.

[19] Curkovic, L., Rede, V., Grilec, K.J. and Mulabdic, A. (2007) Hardness and Fracture Toughness of Alumina Ceramics. Proceedings of the 12th Conference on Materials, Processes Friction and Wear, Vela Luka, 21-23 June 2007, 40-45.

[20] Gubernat, A., Stobierski, L. and Labaj, P. (2007) Microstructure and Mechanical Properties of Silicon Carbide Pressureless Sintered with Oxide Additive. Journal of European Ceramic Society, 27, 781-789. http://dx.doi.org/10.1016/j.jeurceramsoc.2006.04.009

[21] Lee, S., Kim, Y. and Mitomo, M. (2001) Relationship between Microstructure and Fracture Toughness of Toughened Silicon Carbide Ceramics. Journal of American Ceramic Society, 84, 1347-1353. http://dx.doi.org/10.1111/j.1151-2916.2001.tb00840.x

[22] Wang, J. and Stevens, R. (1989) Review Zirconia-Toughened Alumina (ZTA) Ceramics. Journal of Material Science, 24, 3421-3440. http://dx.doi.org/10.1007/BF02385721

[23] Flinders, M., Ray, D., Anderson, A. and Cutler, R.A. (2005) High Toughness Silicon Carbide as Armor. Journal of American Ceramic Society, 88, 2221-2226. http://dx.doi.org/10.1111/j.1551-2916.2005.00415.x

[24] Ritter Jr., J.E., Jakus, K., Bataki, A. and Bandyopadhyay, N. (1980) Appraisal of Biaxial Strength Tests. Journal of Non-Crystalline Solids, 38 \& 39, 419-424. http://dx.doi.org/10.1016/0022-3093(80)90455-X

[25] Medvedovski, E. (2006) Lightweight Ceramic Composite Armour System. Journal of Advances in Applied Ceramics, 105, 241-245. http://dx.doi.org/10.1179/174367606X113537

[26] Nakamura, S., Tanaka, S., Kato, Z. and Uematsu, K. (2009) Strength-Processing Defects Relationship Based on Micrographic Analysis of Fracture Mechanic in Alumina Ceramics. Journal of American Ceramic Society, 92, 688693. http://dx.doi.org/10.1111/j.1551-2916.2008.02904.x

[27] Huang, S., Binner, J., Vaidhyanathan, B., Brown, P., Hampson, C. and Spacie, C. (2011) Development of Nano Zirconia Toughened Alumina for Ceramics Armour Application. Advances in Ceramic Armor VII: Ceramic Engineering and Science Proceedings, 32, 103-114. http://dx.doi.org/10.1002/9781118095256.ch10

[28] Kesharaja, M. and Nagarajah, R. (2014) Determination of Density Variation and Microstructure in Reaction-Sintered SiC Ceramics Using Ultrasonic Time-of-Flight. International Journal of Applied Ceramic Technology, 11, 303-310. http://dx.doi.org/10.1111/ijac.12005

[29] Szutkowska, M. (2012) Fracture Toughness of Advanced Alumina Ceramics and Alumina Matrix Composites Used for Cutting Tool Edges. Journal of Achievements in Materials and Manufacturing Engineering, 54, 202-210.

[30] Zimmermann, K. and Schneider, G.A. (2009) Elastic to Elastic-Plastic Transition of $\mathrm{Al}_{2} \mathrm{O}_{3} / \mathrm{TiC}$ Ceramics Studies by Nano Indentation. Journal of Materials Research, 24, 1960-1966. http://dx.doi.org/10.1557/jmr.2009.0234

[31] Casellas, D., Rafols, I., Llanes, L. and Anglada, M. (1999) Fracture Toughness of Zirconia-Alumina Composites. International Journal of Refractory Metals \& Hard Materials, 17, 11-20. http://dx.doi.org/10.1016/S0263-4368(98)00064-X

[32] Silva, M.V., Stainer, D., Al-Qurshi, H.A., Montedo, O.R.K. and Hotza, D. (2014) Alumina-Based Ceramics for Armour Application: Mechanical Characterisation and Ballistic Testing. Journal of Ceramics, 2014, 1-6.

[33] Karandikar, P.G., Evans, G., Wong, S. and Aghajanian, M. (2010) Effect of Grain Size, Shape and Second Phases on Properties of Sintered SiC: Material Concepts, Processes and Characterisation. Advanced in Ceramic Armor V Ceramic Engineering and Science Proceedings, 30, 69-81. http://dx.doi.org/10.1002/9780470584330

[34] Demirbas, M.V. (2008) Microstructure-Property Relationship in Silicon Carbide Armour Ceramics. PhD Thesis, Materials Science and Engineering, the State University of New Jersey.

[35] Horsfall, I., Edwards, M.R. and Hallas, M.J. (2010) Ballistic and Physical Properties of Highly Fractured Alumina. Journal of Advances in Applied Ceramics, 109, 498-503. http://dx.doi.org/10.1179/174367610X12804792635341 